\title{
Bisphosphonate-Associated Osteonecrosis of the Jaw
}

Sundeep Khosla, David Burr, Jane Cauley, David W Dempster, Peter R Ebeling, Dieter Felsenberg, Robert F Gagel, Vincente Gilsanz, Theresa Guise, Sreenivas Koka, Laurie K McCauley, Joan McGowan, Marc D McKee, Suresh Mohla, David G Pendrys, Lawrence G Raisz, Salvatore L Ruggiero, David M Shafer, Lillian Shum, Stuart L Silverman, Catherine H Van Poznak, Nelson Watts, Sook-Bin Woo, Elizabeth Shane, American Society for Bone and Mineral Research

\section{Source}

Sundeep Khosla, David Burr, Jane Cauley, David W Dempster, Peter R Ebeling, Dieter Felsenberg. (2007).

Bisphosphonate-Associated Osteonecrosis of the Jaw: Report of a Task Force of the American Society for Bone and Mineral Research. J Bone Miner Res, vol. 22 (10), 1479-1491. doi:10.1359/jbmr.0707onj.

Bisphosphonate-associated ONJ was defined as an area of exposed bone in the maxillofacial region that did not heal within 8 wk after identification by a health care provider, in a patient who was receiving or had been exposed to a bisphosphonate and had not had radiation therapy to the craniofacial region. 